\title{
Effect of various amount of mmonium hydroxide on morphology of silica nanoparticles grown by sol-gel
}

\author{
Farah Shahirah Norazmi ${ }^{*}$, a, Kashif Tufail Chaudhary a, b, Elham Mazalan ${ }^{\mathrm{b}}$, Zuhaib Hader a \\ Jalil Ali a, b \\ a Laser Center, Ibnu Sina Institute for Scientific and Industrial Research, Universiti Teknologi Malaysia, 81310 UTM Johor Bahru, Johor, Malaysia \\ b Department of Physics, Faculty of Science, Universiti Teknologi Malaysia, 81310 UTM Johor Bahru, Johor, Malaysia \\ *Corresponding author: fasha43@gmail.com
}

\section{Article history}

Received 3 May 2018

Revised 25 August 2018

Accepted 11 September 2018

Published Online 25 October 2018

\begin{abstract}
Silica nanoparticles have drawn significant intentions for their potential in solar cell coating applications. These products occupy a noticeable position in a scientific research because of their easy preparation and wide uses for different technological applications. The quality of silica nanoparticles are highly dependent on the size. This study reports the synthesis of monodisperse silica nanoparticles by hydrolysis of tetraethyl orthosilicate (TEOS) in a mixture of ethanol and DI water as a solvent and ammonium hydroxide solution $\left(\mathrm{NH}_{4} \mathrm{OH}\right)$ as a catalyst. The solutions are stirred overnight and dried in a low-pressure furnace under 100 mbar for 3 hours at $60^{\circ} \mathrm{C}$. Various-sized silica nanoparticles in the range $80 \mathrm{~nm}-250 \mathrm{~nm}$ were examined under field emission scanning electron microscopy (FESEM). With the increasing volume of ammonia solution, an increase in the size of silica nanoparticles were observed.
\end{abstract}

Keywords: Silica nanoparticles; sol-gel; field emission scanning electron microscopy

\section{INTRODUCTION}

Silica nanoparticles are favorable for science and technology fields in electronic, aerospace, defense, medical and prominent areas in scientific researches. The designing, synthesis, characterization and application of materials and devices on nanometer scale have made ceramic nanoparticles into new classes of advanced materials which meet the demands from high-tech applications. Many researchers have been studying the silica because of their simple preparation and extensive uses and also, they are favorably subject on the size distribution of these particles [1][2].

Stober et al. [3] developed spherical silica particles of uniform in micron sizes between $0.05 \mu m-2 \mu \mathrm{m}$ by a chemical reactions of hydrolysis of alkyl silicates and subsequent condensation of silicic acid alcoholic solutions. The formation of silicas have achieved by two main mechanisms which are nucleation and growth [2][4]. The particles or nuclei aggregate with one another or larger aggregates by ammoniacatalyzed reactions of TEOS with water in low-molecular-weight alcohols which produced monodisperse and spherical silica nanoparticles [3]. In general, the hydrolysis and condensation reactions are given as [2][5][6],

$$
\begin{aligned}
& \equiv S i-O R+H 2 O \leftrightarrow \text { hydrolysis } \\
& \equiv S i-O H+R O H \\
& \equiv S i-O R+\equiv S i-O H \leftrightarrow \text { alcohol condensation } \\
& \equiv S i-O-S i+R O H
\end{aligned}
$$

$$
\begin{aligned}
& \equiv S i-O H+\equiv S i-O H \leftrightarrow \text { water condensation } \\
& \equiv S i-O-S i \equiv+H 2 O
\end{aligned}
$$

where $\mathrm{R}$ is an alkyl group $\mathrm{C}_{\mathrm{x}} \mathrm{H}_{2 \mathrm{x}+1}$. For (Eq.(1])), the hydrolysis of alkoxide groups (OR) were substituted by hydroxyl groups $(\mathrm{OH})$. The condensation reactions between the silanol groups and ethoxy groups or between silanol groups yield siloxane bridges $(\mathrm{Si}-\mathrm{O}-\mathrm{Si}$ ) and either alcohol (ROH) for (Eq.(2)) and water (H2O) for (Eq.(3)).

More recently, Meier et al. [7] have used ethanolamine as a replacement of the basic catalyst ammonia via a modified Stober synthesis route to produce nanometric silica particles in alkaline media at elevated reaction temperatures. The use of ethanolamine in a sealed reaction tubes as a modified Stober synthesis inherent a good agreement of reaction kinetics that resulting the spherical silica nanoparticles with diameters between $28-647 \mathrm{~nm}$ at high temperatures and ambient pressure. In addition, Petcu et al. analyzed the drying of the silica from the volatile compounds and dispersed in ethanol in a vacuum state at ambient temperature and formed $\sim 150 \mathrm{~nm}$ diameter silica nanoparticles in spherical shape. Rahman et al. reported [8] the higher ratio of $\mathrm{H}_{2} \mathrm{O} / \mathrm{TEOS}$ and lower ammonia concentration at slower feed rate produced particles in the range of $10-14 \mathrm{~nm}$. The homogeneous and stable silica nanoparticles size were controlled by the optimum experimental conditions such as concentration of the reactants, ammonia feed rate, temperature and mixing mode. Besides that, the addition of small amount of anion electrolytes such as $\mathrm{Br}$ - and I- have the highest effect on reducing the particle size by $73 \%-78 \%$ and were free from contamination [9]. In this study, the effect of the volume of ammonium hydroxide on the morphology and the size of the silica nanoparticles grown modified Stober method under a vacuum state was studied. 


\section{EXPERIMENTAL}

\section{Materials}

Tetraethyl orthosilicate (TEOS, 99\%), ethanol (extra pure), distilled water and ammonium hydroxide $\left(\mathrm{NH}_{4} \mathrm{OH}, 28 \%\right)$ were used as received without further retreatment.

\section{Synthesis of silica nanoparticles}

The silica nanoparticles were prepared by hydrolysis of TEOS (6.9 $\mathrm{ml})$ and ethanol $(15 \mathrm{ml})$ that were initially introduced in 3 different of $30 \mathrm{ml}$ vials with continuous stirring on the stirrer (400 rot $/ \mathrm{min})$. While stirring, a mixture of DI water $(2.20 \mathrm{ml})$ and various amount of ammonium hydroxide solution $(0.5 \mathrm{ml}, 1.0 \mathrm{ml}$ and $1.50 \mathrm{ml})$ were added into each vials after 10 minutes and kept stirring for 4 hours until the mixture turned into milky solution. Then, the 3-different mixtures were put into the petri dishes and dried in the tube furnace at low pressure (100 mbar) at $60^{\circ} \mathrm{C}$ for 3 hours. After drying, about $1 \mathrm{~g}$ of silica nanoparticles for each petri dishes were obtained and characterized.

\section{Characterization}

The structure and the particle size of silica nanoparticles were observed and measured using Field Emission Scanning Electron Microscopy (FESEM). The samples have been coated with gold and the micrographs were taken at 3 random spots.

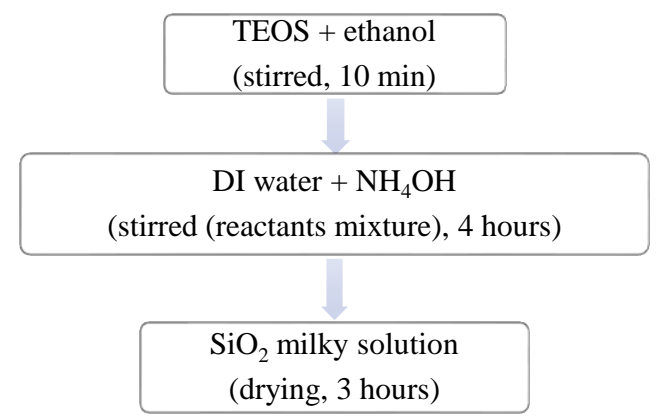

Fig. 1 Flow chart of preparation of silica nanoparticles.

\section{RESULTS AND DISCUSSION}

\section{Synthesis of silica nanoparticles}

A systematic experiment was carried out by sol-gel process via Stober synthesis route [7] and the results are discussed. The preparation of different series of silica nanoparticles (samples a, b, c) stated in Table 1. The size of the silica nanoparticles, which were controlled by the volume of $\mathrm{NH}_{4} \mathrm{OH}$ was one of the parameters that show a vital role in the size distribution of silica nanoparticles.

The FESEM micrographs of each samples are shown in Fig 2. The size of the silica nanoparticles were measured by FESEM and Image J where compatible. Three spots were taken at each samples to get the uniformity of the average particle sizes. Ammonium hydroxide acts as a catalyst for hydrolysis and condensation of TEOS in ethanol escalating the rate of the reaction. The decreasing volume of ammonium hydroxide with decreasing weight ratio $(20.4 \%, 13.6 \%$ and $6.8 \%$ ) led to smaller size of the silica nanoparticles. The decreasing volume of ammonium hydroxide in the mixture of TEOS, ethanol and DI water ensures the constant concentration of ammonia (25M) which formed the smaller silica nanoparticles.

Table 1 Preparation of different size silica nanoparticles.

\begin{tabular}{cccccc}
\hline Samples & $\begin{array}{c}\text { TEOS } \\
(\mathbf{m l})\end{array}$ & $\begin{array}{c}\mathbf{C}_{2} \mathrm{H}_{5} \mathrm{OH} \\
(\mathbf{m l})\end{array}$ & $\begin{array}{c}\text { DI } \\
\text { water } \\
(\mathbf{m l})\end{array}$ & $\begin{array}{c}\mathbf{N H}_{4} \mathrm{OH} \\
(\mathbf{m l})\end{array}$ & $\begin{array}{c}\text { Average } \\
\text { particle } \\
\text { size } \\
(\mathbf{n m})\end{array}$ \\
\hline a & 6.9 & 15 & 2.2 & 1.5 & 214.1 \\
b & 6.9 & 15 & 2.2 & 1.0 & 162.4 \\
c & 6.9 & 15 & 2.2 & 0.5 & 93.5 \\
\hline
\end{tabular}

As seen in Fig. 2, the structure of the silica particles for each samples was different in terms of the diameter. The particles were bigger in sample a which is in average size between $150 \mathrm{~nm}-250 \mathrm{~nm}$ with the highest amount of ammonium hydroxide compared to the samples b $(100 \mathrm{~nm}-160 \mathrm{~nm})$ and $\mathrm{c}(80 \mathrm{~nm}-100 \mathrm{~nm})$ due to the controlled aggregation. The addition of monomer triggered the nucleation growth of the particles and continuously reacted resulting the particles to aggregate together and form larger particles [5][2]. Besides that, according to Szekers et al [10], high concentration of water enlarged the size of the particles. This was due to the high nucleation rate of the hydrogen bond of $\mathrm{SiO}_{2}$ that causes the agglomeration and ended with the large particles as shown in Fig. 3.

The solubility of the nanoparticles were essentially liable to agglomeration of the powder especially during the drying process [11]. A thorough process hints the formation of well-dispersed particles, whereas drying in the presence of water could outcome in agglomeration phenomenon [5]. This was as of the particle behavior from the condensation reactions at interparticle contacts throughout the drying process and also could be the Brownian motion and hydrodynamic effect. Thus, the ethanol was used as the suspension medium to moderate the agglomeration effect but somehow the amount of the ethanol did not show a major role in order to acquire monodispersed and smaller size particles when raising the volume of the ammonia, as presented in Fig.2. However, these silica nanoparticles were dried in a tube furnace at low pressure $(100 \mathrm{mbar})$ which accelerated the drying process at $60^{\circ} \mathrm{C}$.
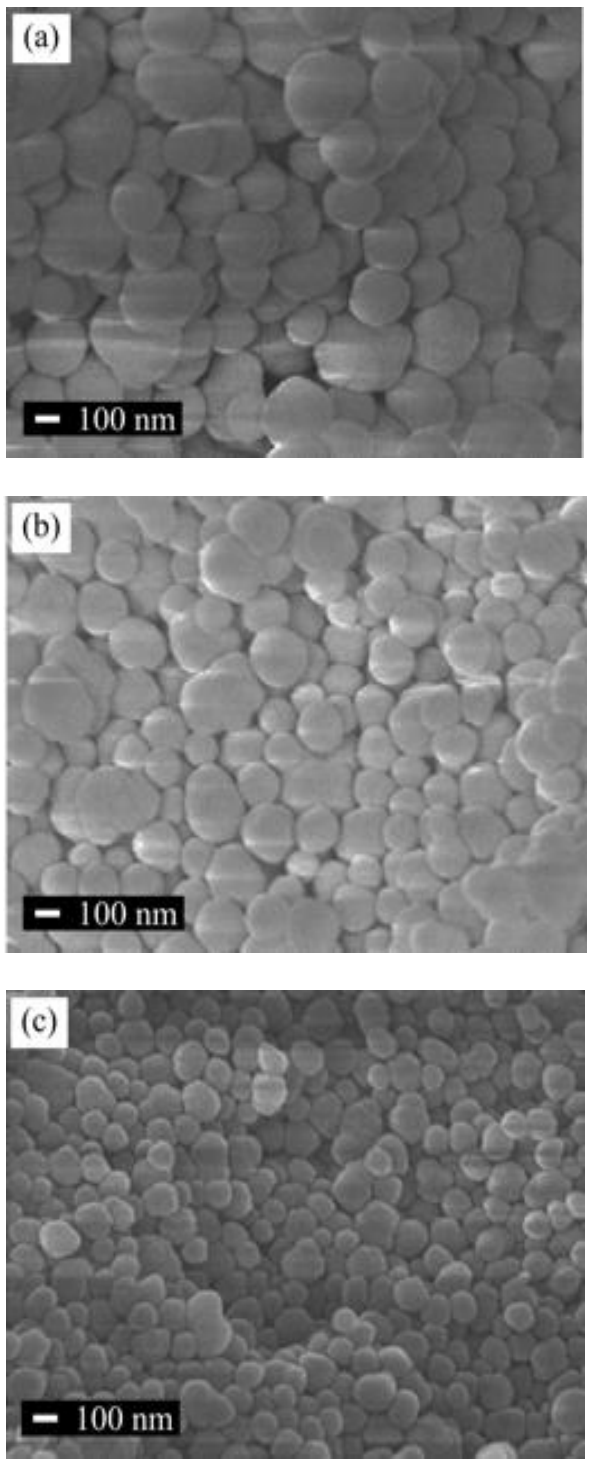

Fig. 2 FESEM images of silica nanoparticles synthesized by sol-gel method. 


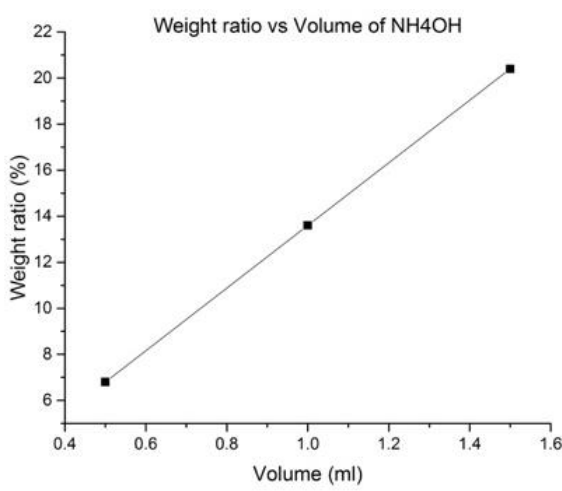

(a)

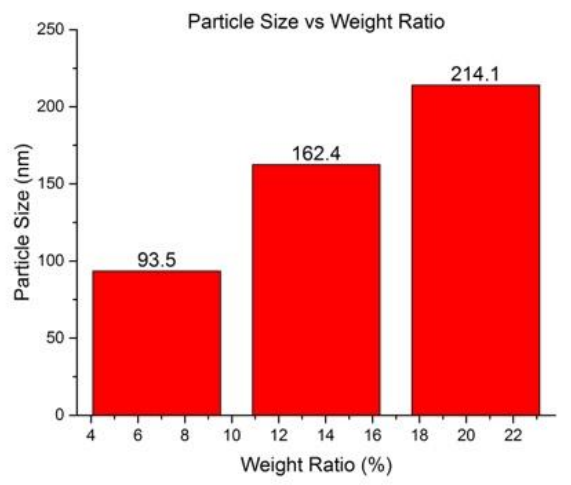

(b)

Fig. 3 (a) Relationship between volume and concentration of $\mathrm{NH}_{4} \mathrm{OH}$, (b) Effect of $\mathrm{NH}_{4} \mathrm{OH}$ on average particle size

\section{CONCLUSION}

The present method is a convenient modification of Stober method conducted in a vacuum state at low temperature to produced various size of silica nanoparticles. The use of the ethanol as a solvent and ammonium hydroxide as a catalyst allows silica to form into spherical shape and well controllable diameters between 80 to $250 \mathrm{~nm}$.

\section{ACKNOWLEDGEMENT}

We would like to thank Ibnu Sina Institute for Scientific and Industrial Research (ISI-SIR), Universiti Teknologi Malaysia (UTM) and Microelectronics and Nanotechnology - Shamsuddin Research Centre (MiNT-SRC), Universiti Tun Hussein Onn Malaysia (UTHM) for providing research facilities. This research work has supported by Tier 1 (12H82) Grant.

\section{REFERENCES}

K. S. Rao, K. El-Hami, T. Kodaki, K. Matsushige, and K. Makino, "A novel method for synthesis of silica nanoparticles," J. Colloid Interface Sci., vol. 289, no. 1, pp. 125-131, 2005.

D. L. Green, J. S. Lin, Y. F. Lam, M. Z. C. Hu, D. W. Schaefer, and M. T. Harris, "Size, volume fraction, and nucleation of Stober silica nanoparticles," $J$. Colloid Interface Sci., vol. 266, no. 2, pp. 346-358, 2003.

M. T. Harris, R. R. Brunson, and C. H. Byers, "The base-catalyzed hydrolysis and condensation reactions of dilute and concentrated TEOS solutions," $J$. Non-Cryst. Solids, vol. 121, no. 1-3, pp. 397-403, 1990.

B. Topuz, D. Şimşek, and M. Çiftçiołlu, "Preparation of monodisperse silica spheres and determination of their densification behaviour," Ceram. Int., vol. 41, no. 1, pp. 43-52, 2014.

I. A. Rahman and V. Padavettan, "Synthesis of silica nanoparticles by sol-gel: Size-dependent properties, surface modification, and applications in silicapolymer nanocompositesa review," J. Nanomater., vol. 2012, 2012.

G. H. Bogush and C. F. Zukoski IV, "Studies of the kinetics of the precipitation of uniform silica particles through the hydrolysis and condensation of silicon alkoxides," J. Colloid Interface Sci., vol. 142, no. 1, pp. 1-18, 1991.

M. Meier, J. Ungerer, M. Klinge, and H. Nirschl, "Synthesis of nanometric silica particles via a modi fi ed Stöber synthesis route," Colloids Surfaces A, vol. 538, no. September 2017, pp. 559-564, 2018.

I. A. Rahman et al., "An optimized sol-gel synthesis of stable primary equivalent silica particles," Colloids Surfaces A Physicochem. Eng. Asp., vol. 294, no. 13, pp. 102-110, 2007.

I. A. Rahman et al., "Effect of anion electrolytes on the formation of silica nanoparticles via the sol-gel process," Ceram. Int., vol. 32, no. 6, pp. 691699, 2006.

M. Szekeres et al., "Ordering and optical properties of monolayers and multilayers of silica spheres deposited by the Langmuir-Blodgett method," $J$. Mater. Chem., vol. 12, no. 11, pp. 3268-3274, 2002.

S. Kwon and G. L. Messing, "The effect of particle solubility on the strength of nanocrystalline agglomerates: Boehmite," Nanostructured Mater., vol. 8, no. 4, pp. 399-418, 1997. 